\title{
Indirect inguinal hernia with uterine tissue in a male: A case of persistent Mullerian duct syndrome and literature review
}

\author{
Michael Ahdoot, BA, BS, ${ }^{*}$ Motaz Oadan, MD, PhD; ${ }^{*}$ Monica Santa-Maria, MD; ${ }^{\dagger}$ William A. Kennedy II, MD;* \\ Aaron llano, $M D^{+}$
}

*Stanford University Medical Center and Stanford University School of Medicine, Stanford, CA; †Kaiser Santa Clara, Santa Clara, CA

Cite as: Can Urol Assoc J 2013;7:E121-E124. http://dx.doi.org/10.5489/cuaj|.253

\section{Abstract}

\begin{abstract}
A 32-year-old male presenting with a direct inguinal hernia was found to have uterine tissue extending through the inguinal canal, warranting a diagnosis of persistent Mullerian duct syndrome (PMDS). PMDS is an extremely rare form of internal male pseudohermaphroditism in which female internal sex organs, including the uterus, cervix and proximal vagina, persist in a 46XY male with normal external genitalia. The condition results from a congenital insensitivity to anti-Mullerian hormone, or lack of anti-Mullerian hormone, leading to persistence of the female internal sex organs in a male. Clinically, this condition is associated with cryptochoridism. Controversy persists regarding the appropriate treatment of PMDS, since resection of the remnant structures is associated with potential morbidity, but retention risks development of occasional malignancies. We review the literature and discuss various aspects of pathophysiology, diagnosis, and management of PMDS.
\end{abstract}

\section{Case presentation}

A 32-year-old gentleman was referred to the general surgery clinic for a painful right groin mass. The patient described the pain as dull and persistent with no clear exacerbating factors. As an infant, he had a history of a right inguinal hernia and a left undescended testicle. At 1 year of age, he underwent right inguinal hernia repair and left orchiectomy. There was no additional surgical or medical history. Physical examination demonstrated a well-appearing male with a well-healed right groin scar overlying a reducible groin mass with palpable cough impulse. The right testis was of normal size, with no palpable masses, and normally located within the right hemiscrotum. The left testicle was absent and with no evidence of a detectable hernia. The abdominal examination was entirely unremarkable. The patient was diagnosed with a recurrent right-sided inguinal hernia, and open mesh repair of the hernia was planned.

Following informed consent, the patient had surgery. A 4-cm surgical incision was made at the right groin crease. Contents of the inguinal canal, in particular, the right spermatic cord, were identified as emerging from the right internal inguinal ring. Adjacent to the spermatic cord, however, an unidentified tubulo-muscular structure passing from the internal inguinal ring could be seen (Fig. 1). A small incision was made within the structure and flexible endoscopy demonstrated a hollow tubular structure that eventually led to a blind end (Fig. 2). Contrast was passed into the tubular structure and intra-operative radiographs revealed that the structure continued into a blind end within the pelvis. Communication within the prostatic urethra, but not the bladder, was evident. At this point, a decision was made to excise the structure at its point of exit from the inguinal canal. It measured about $10 \mathrm{~cm}$ in length and $2 \mathrm{~cm} \times 2 \mathrm{~cm} \times 3 \mathrm{~cm}$ at its proximal end (Fig. 3). It was seen to contain mucus only. The indirect hernia was subsequently repaired using a standard Lichtenstein repair with a plug and patch mesh. There were no perioperative complications.

Subsequent pathological evaluation of the excised structure identified poorly developed endometrium and myometrium, consistent with uterine tissue (Fig. 4, Fig. 5). The patient underwent genotypic analysis, which revealed a normal 46XY karyotype, as well as computed-tomography (CT) scanning of the abdomen and pelvis, which was unremarkable. He had an uneventful follow-up visit in the general surgery clinic 1 month later, and was discharged from surgical care without further routine follow-up. The diagnosis was persistent Mullerian duct syndrome (PMDS). 


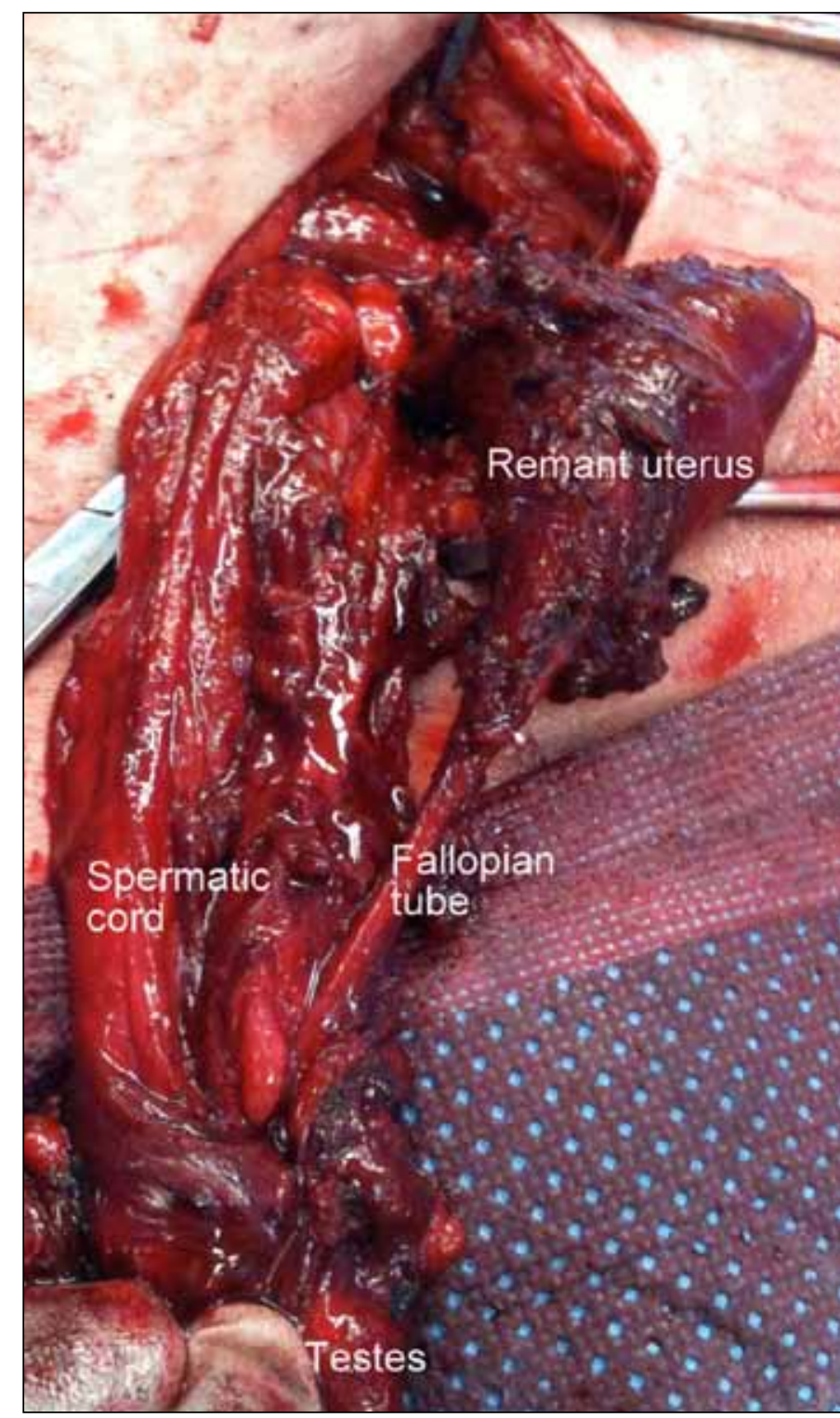

Fig. 1. Tubulo-muscular structure shown to the right of the spermatic cord originating from the internal inguinal ring. Class B persistent Mullerian duct syndrome characterized by presence of fallopian tubes and uterus in one hemiscrotum and an undescended testis tethered to fallopian tube on the contralateral side.

\section{Discussion}

PMDS is an extremely rare form of internal male pseudo-hermaphroditism in which female internal sex organs, including the uterus, cervix and proximal vagina (terminating in the prostatic utricle), persist in a 46XY male with normal external genitalia. The persistent Mullerian structures often tether the testes and impede their descent, causing unilateral or bilateral undescended testicles. The condition was first described in 1895, with about 200 cases described in the literature since. ${ }^{1}$

In normal fetal sex organ development, the Wolffian and Mullerian ducts give rise to male and female internal sex

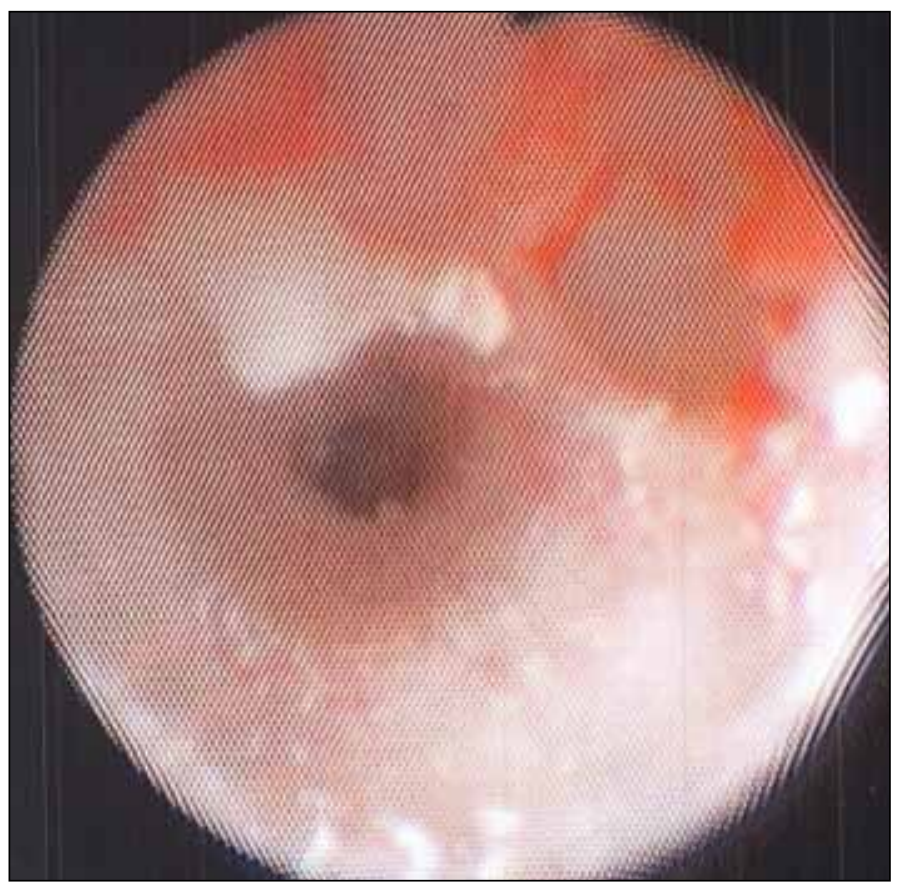

Fig. 2. Flexible endoscopic view of tubular structure demonstrating a smooth musuclar structure extending into the pelvis.

organs, respectively. During the eighth and ninth weeks of male fetal development, Sertoli cells produce an anti-Mullerian hormone $(\mathrm{AMH})$, also known as Mullerian inhibiting factor or substance (MIF/MIS). This hormone induces regression of the Mullerian ducts, thereby inhibiting the development of the uterus, cervix, proximal vagina and fallopian tubes. Testosterone produced by Leydig cells subsequently induces virilization of the Wolffian ducts into epididymides, vasa deferentia and seminal vesicles. External male genitalia development is largely under the control of dihydrotestosterone (DHT). ${ }^{2}$ In males, failure to produce functional $\mathrm{AMH}$ or a defective type II AMH receptor (AMHRII) leads to failure of Mullerian duct regression. ${ }^{3}$ The Mullerian structures thus develop into uterus, upper vagina, and fallopian tubes in a 46XY male with normal male external genitalia, leading to PMDS. ${ }^{4}$ In $15 \%$ of patients, the cause of PMDS is unknown. However, in the remaining $85 \%$ of cases, autosomal recessive inheritance of defects in $\mathrm{AMH}$ (chromosome 19) and its receptor AMHR-II (chromosome 12) account for development of PMDS. ${ }^{5}$ In males, virilization generally remains unaffected, but infertility is common secondary to azoospermia. ${ }^{6}$ Homozygous mutations in AMH or AMHR-II have been linked with premature loss of germ cells in female mouse models. However, homozygous human females are normal and fertile at least in early reproductive life. ${ }^{2}$

Clinically, PMDS is most commonly diagnosed as an incidental finding during an operation, but the presence of unilateral or bilateral undescended testes may increase clinical suspicion..$^{711}$ Imaging modalities for the diagnosis of PMDS have thus far proven unreliable. ${ }^{12}$ Most (60\%-70\%) 


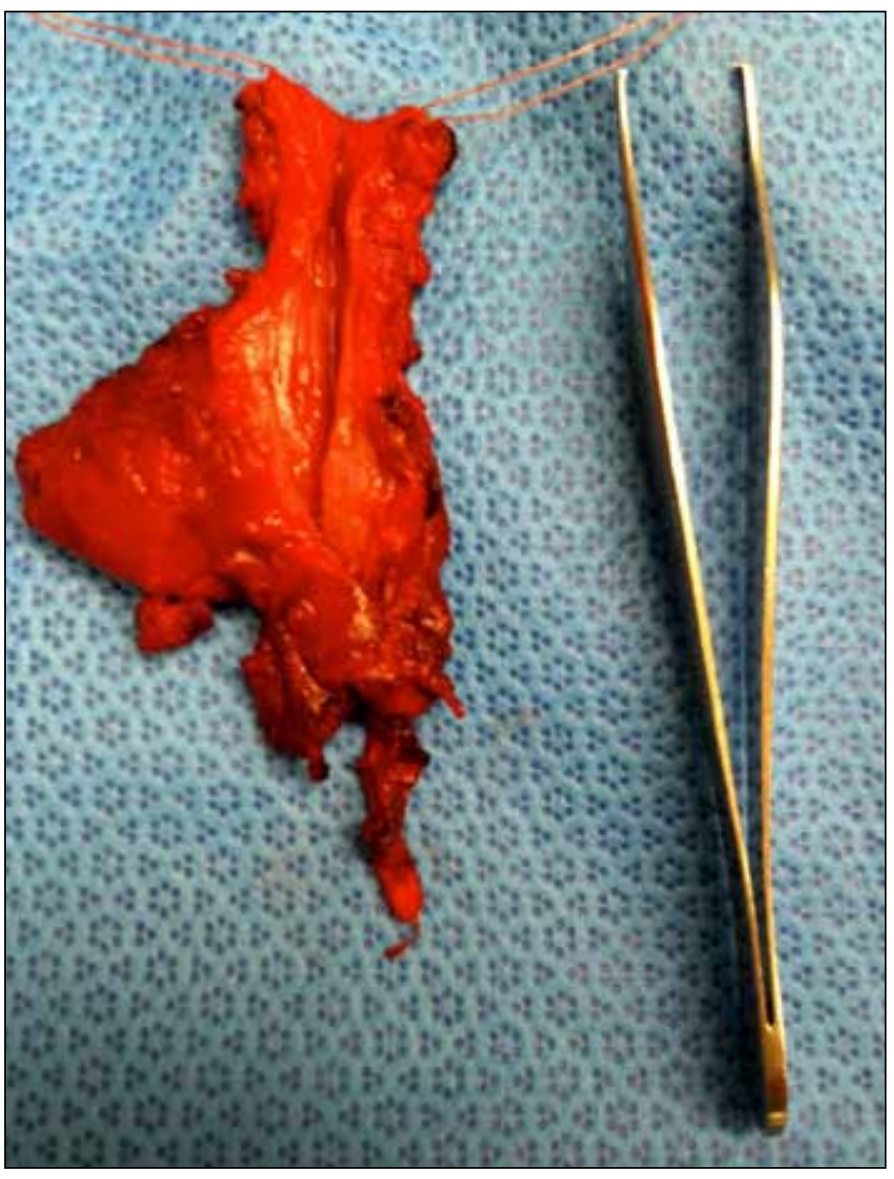

Fig. 3. Excised uterine tissue shown alongside Adson forceps.

of patients with PMDS have bilateral undescended testes located in an area analogous to the ovaries in women. ${ }^{13}$ This specific form of PMDS is occasionally referred to as class A, or the "female" form, of PMDS. ${ }^{14}$ A second $20 \%$ to $30 \%$ of patients present with a unilateral testis contained within a hernia sac or hemiscrotum, with a contralateral undescended testis and inguinal hernia, this being known as class B PMDS (Fig. 1). Many class B PMDS patients, such as the patient reported in this case, have a fallopian tube and uterus herniating through the inguinal canal, a condition classically described as "hernia uteri inguinale." In class $\mathrm{C}$ PMDS, seen in the remaining $10 \%$ of patients, both testes (along with the fallopian tubes and uterus) herniate into the same hemiscrotum, a condition known as "transverse testicular ectopia." 15,16 About $30 \%$ to $50 \%$ of all cases of transverse testicular ectopia are thought to be secondary to PMDS. ${ }^{17}$ Rarely, the second testis will become entrapped in the inguinal canal ipsilateral to the normally descended testis. ${ }^{18}$

Management of PMDS is controversial. An element of deciding on intervention is largely based on reducing the risk of malignancy, while maintaining maximal reproductive function. In PMDS patients with undescended testes,

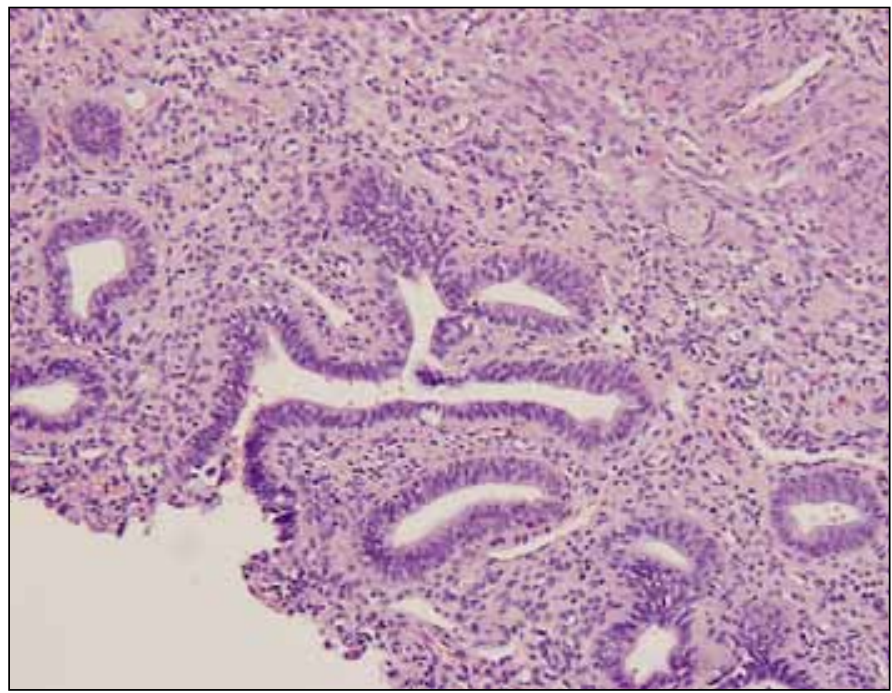

Fig. 4. The central lumen is lined by pseudostratified monomorphic columnar cells with light eosinophilic cytoplasm, elongated nuclei and small nucleoli. 0 ccasional cilia are seen on epithelial cells. Stroma surrounds the epithelial component. The morphologic features are consistent with a uterus with poorly developed endometrium and myometrium.

the rate of testicular cancer is about $12 \%$, which is comparable to the rate seen in undescended testes not associated with PMDS. To detect testicular disease, as with any case of undescended testis, orchiopexy is indicated after 12 months of age. ${ }^{1,19}$ In addition, orchiopexy may be attempted for cases of bilateral cryptorchidism, with hopes of preserving fertility and testosterone production. Unilateral or bilateral cryptorchidism in adults should be treated with orchiectomy, as orchiopexy of the testes is unlikely to preserve fertility or lead to sufficient testosterone production to forego hormonal replacement.

Beyond orchiopexy, the decision to resect the Mullerian structures depends largely on maximizing testicular function

\section{Table 1. Key points}

- Persistent Mullerian duct syndrome (PMDS) is typically a rare autosomal recessive disorder caused by non-functional mutations in anti-Mullerian hormone or its type II receptor.

- Clinically, PMDS is defined as the presence of Mullerianderived structures (uterus, fallopian tubes, and proximal vagina) inserting at the prostatic utricle in a normal $46 \mathrm{XY}$ male with normal appearing external genitalia. This condition is often associated with unilateral or bilateral undescended testicles.

- Undescended testes in PMDS patients have a similar risk of developing testicular cancers as patients with non-PMDS intra-abdominal testes, quoted at about $12 \%$.

- Surgical management of PMDS is controversial, and focuses on management of undescended testes with possible removal of Mullerian structures, but only if resection of the structures does not impair testicular function, or damage the vas deferens, through damage to the blood supply during dissection. 


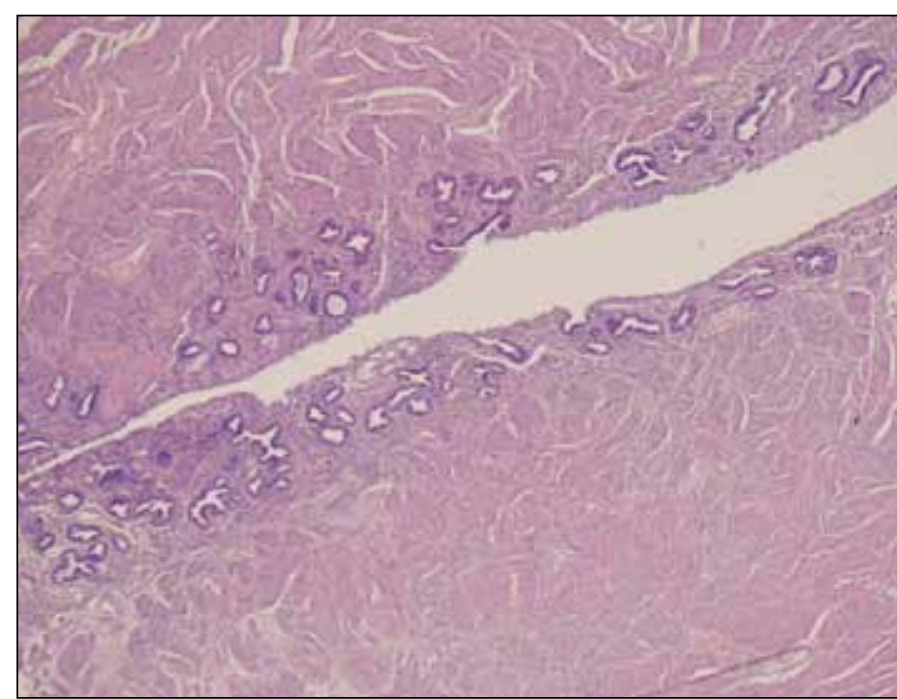

Fig. 5. The central lumen is lined by pseudostratified columnar cells with muscle bundles seen deep to this layer. The morphologic features are consistent with a uterus with poorly developed endometrium and myometrium.

and minimizing morbidity. Several authors have asserted that the Mullerian structures should not be removed, as there is minimal risk associated with their retention, and excision of the Mullerian structures risks damaging primary blood supply to the PMDS testis via the internal spermatic and the deferential arteries. ${ }^{9}$ However, more recent reports have demonstrated rare malignancies, usually adenocarcinomas of the Mullerian duct, associated with retained Mullerian structures. ${ }^{20-26}$ If resection is attempted, great care must be taken to avoid damage to the vascular supply to the testis, or vas deferens, which run in close proximity to the remnant uterus and proximal vagina. ${ }^{9}$ Interestingly, laparoscopic management of PMDS has now also been successfully reported. ${ }^{27,28}$ See Table 1 for our key points.

Competing interests: None declared.

This paper has been peer-reviewed.

\section{References}

1. Berkmen F. Persistent Müllerian duct syndrome with or without transverse testicular ectopia and testis tumours. Br J Urol 1997;79:122-6. http://dx.doi.org/10.1046/j.1464-410X.1997.27226.x

2. Josso N. Biology and genetics of anti-Mullerian hormone. In: New MI, Simpson JL, eds. Hormonal and Genetic Basis of Sexual Differentiation Disorders and Hot Topics in Endocrinology: Proceedings of the 2nd World Conference. Vol 707. New York, NY: Springer New York; 2011:83-5.

3. Rey RA, Grinspon RP. Normal male sexual differentiation and aetiology of disorders of sex development. Best Pract Res Clin Endocrinol Metab 2011;25:221-38. http://dx.doi.org/10.1016/i.beem.2010.08.013

4. Josso N. Paediatric applications of anti-mullerian hormone research. Horm Res 1995;43:243-8. http:// dx.doi.org/10.1159/000184300
5. Imbeaud S, Belville C. A 27 base-pair deletion of the anti-Müllerian type II receptor gene is the most common cause of the persistent Müllerian duct syndrome. Hum Mol Genet 1996;5:1269-77. http:// dx.doi.org/10.1093/hmg/5.9.1269

6. Martin EL, Bennett AH, Cromie WJ. Persistent müllerian duct syndrome with transverse testicular ectopia and spermatogenesis. J Urol 1992;147:1615-7.

7. Crankson SJ, Bin Yahib S. Persistent Mullerian duct syndrome in a child: surgical management. Ann Saudi Med 2000;20:267-9.

8. Wu H-C, Chen J-H, Lu H-F, et al. Persistent Mullerian duct syndrome with seminoma: CT findings. Am J Roentgenol 2000; 174:102-4.

9. Vandersteen DR, Chaumeton AK, Ireland $K$, et al. Surgical management of persistent Müllerian duct syndrome. Urology 1997;49:941-5. http://dx.doi.org/10.1016/S0090-4295(97)00104-0

10. Gutte AA, Pendharkar PS, Sorte SZ. Transverse testicular ectopia associated with persistent Mullerian duct syndrome - the role of imaging. Br J Radiol 2008;81:e176-8. http://dx.doi.org/10.1259/ bir/76916885

11. Diamond DA, Yu RN. Campbell-Walsh Urology. Wein AJ, Kavoussi LR, Novick AC, Partin AW, Peters CA, eds. Philadelphia, PA: Elsevier Inc; 2011:3597-628.

12. Gökce $M$, Burgu B, Aydogdu Ö, et al. Transverse testicular ectopia associated with persistent Müllerian duct syndrome: another entity in which magnetic resonance imaging is unreliable. Urology 2010;76:1475-7. http://dx.doi.org/10.1016/j.urology.2010.03.043

13. Demir 0 , Kizer 0 , Sen $V$, et al. Persistent Mullerian duct syndrome in adult men diagnosed using laparoscopy. Urology 2011;78:566. http://dx.doi.org/10.1016/j.urology.2010.11.015

14. Hutson JM, Chow CW, Ng WD. Persistent Mullerian duct syndrome with transverse testicular ectopia. Pediatr Surg Int 1987;2:191-4. http://dx.doi.org/10.1007/BF00185152

15. Clarnette $T D$, Sugita $Y$, Hutson JM. Genital anomalies in human and animal models reveal the mechanisms and hormones governing testicular descent. Br J Urol 1997;79:99-112. http://dx.doi.org/10.1046/ j. 1464-410X.1997.25622.x

16. Odi T, Abdur-Rahman L, Nasir A. Persistent Mullerian duct syndrome: A case report and review of the literature. Afr J Paediatr Surg 2010;7:191-3. http://dx.doi.org/10.4103/0189-6725.70425

17. Fujita J. Testicular ectopia. Urology 1980;26:400-2. http://dx.doi.org/10.1016/00904295(80)90150-8

18. Motiwale SS, Morreau P, Roadley G. Transverse Testicular Ectopia. Pediatric Endosurgery \& Innovative Techniques 2003;7:339-41. http://dx.doi.org/10.1089/109264103322381799

19. Kazim E. Inta-abdominal seminomas in persistent Mullerian duct syndrome. Urology 1985;26:290-2. http://dx.doi.org/10.1016/0090-4295(85)90129-3

20. Shinmura Y, Ph D, Yokoi T. Case report a case of clear cell adenocarcinoma of the Müllerian duct in persistent Müllerian duct syndrome. Am J Surg Pathol 2002;26:1231-4. http://dx.doi.org/10.1097/00000478200209000-00014

21. Elnemr A, Yonemura Y, Shinbo M, et al. Primary retroperitoneal Mullerian adenocarcinoma. Rare Tumors 2010;2(e6):16-9.

22. Thiel DD, Erhard MJ. Uterine adenosarcoma in a boy with persistent Mullerian duct syndrome: first reported case. J Pediatr Surg 2005;40:e29-31. http://dx.doi.org/10.1016/i.jpedsurg.2005.05.071

23. Romero FR, Fucs M, Castro MGD, et al. Adenocarcinoma of persistent Mullerian duct remnants: case report and differential diagnosis. Urology 2005;66:194-5. http://dx.doi.org/10.1016/.urology.2005.01.024

24. Dekker HM, de Jong IJ, Sanders J, et al. Persistent Müllerian duct syndrome. Radiographics 2003;23:30913. http://dx.doi.org/10.1148/rg.232025141

25. Korashi EE, Tabbakh NME. A Man with Uterine Leiomyoma. Internet J Obstet Gynecol 2002;1. http:// www. ispub.com/journal/the-internet-journal-of-gynecology-and-obstetrics/volume-1-number-2/a-manwith-uterine-leiomyoma.html. Accessed February 12, 2013

26. Warmann SW, Vogel $M$, Wehrmann $M$, et al. Giant Mullerian duct cyst with malignant transformation in 15-year-old boy. Urology 2006;67:424.

27. Lima $M$, Morabito $A$, Libri $M$, et al. Laparoscopic removal of a persistent Mullerian duct in a male: case report. Eur J Pediatr Surg 2001;11:142. http://dx.doi.org/10.1055/s-2001-15471

28. Farikullah J, Ehtisham S, Nappo $S$, et al. Persistent Müllerian duct syndrome: lessons learned from managing a series of eight patients over a 10-year period and review of literature regarding malignant risk from the Müllerian remnants. BJU Int 2012;110(11 Pt C):E1084-9. http://dx.doi.org/10.1111/i.1464410X.2012.11184.x. Epub 2012 Apr 30.

Correspondence: Dr. Motaz Qadan, Department of Surgery, 300 Pasteur Drive, Stanford, CA 94305; mqadan@stanford.edu 